\title{
Deformational behavior and damage mechanism of $R$ - UHPFRC beam subjected to fatigue loading
}

\author{
Bartłomiej Sawicki • Eugen Brühwiler (1) - Antoine Bassil $(\mathbb{C}$
}

Received: 12 October 2020/Accepted: 18 June 2021 / Published online: 12 July 2021

(C) The Author(s) 2021

\begin{abstract}
The fatigue behavior of a reinforced UHPFRC (Ultra High Performance Fiber Reinforced Cementitious composite) T-shaped beam under fourpoint bending is investigated. The beam was subjected to a fatigue loading range equal to $49 \%$ of the static resistance and failed after 0.88 million cycles. It was instrumented with extensometers, strain gauges and distributed fiber optic sensors for strain monitoring. The fatigue process consists of three stages: with rapid, stable and again rapid growth of strains during $10 \%, 80 \%$ and $10 \%$ of total number of fatigue cycles, respectively. Except of the first $10 \%$, this process takes place locally; therefore, it cannot be followed with the deflection measurement. During the stable stage, growth of strain occurs at minimum loading level in the fatigue cycle, indicating a fatigue damage process under tensile-compressive response of UHPFRC. Advanced fatigue crack propagation in the reinforcement bar determines the location of rupture of the
\end{abstract}

B. Sawicki $(\bowtie) \cdot$ E. Brühwiler

Laboratory of Maintenance and Safety of Structures,

Structural Engineering Institute, Swiss Federal Institute of

Technology (EPFL), Lausanne, Switzerland

e-mail: bartek.sawicki@epfl.ch

\section{A. Bassil}

COSYS-SII, I4S Team (Inria), Univ Gustave Eiffel, IFSTTAR, 44344 Bouguenais, France

A. Bassil

Quadric, Artelia Group, 14 Porte de Grand Lyon,

01700 Neyron, France beam. When the remaining cross-section of the rebar does not suffice to carry the tensile load, stress is transmitted to the encompassing UHPFRC causing its fast deterioration. Complete rupture of the rebar occurs only at the end of the test, when the beam collapses.

Keywords UHPFRC $\cdot$ Fatigue - Testing · Cementitious composite · Distributed Fiber Optics Sensing

\section{Introduction}

Novel building materials with high strength allow for design of more slender structures. Consequently, the ratio of external load, e.g. due to traffic, to dead loads, e.g. self-weight, is much higher than in the case of massive structures. Because of that, the fatigue resistance becomes of importance. One of such novel materials is the Ultra High Performance Fiber Reinforced Cementitious composite (UHPFRC) comprising cementitious matrix with small constituents $(<1 \mathrm{~mm})$ and high amount of short fibers $(>3 \%$ vol.), usually made of steel [1]. It is often used with longitudinal reinforcement bars in the direction of highest internal forces, forming reinforced UHPFRC (R-UHPFRC). 
So far, few fatigue tests on R-UHPFRC elements have been reported. A test on a one-meter-long section of pedestrian bridge with GFRP rebars was executed by Parsekian et al. [2], with deflection measurement. Under load cycle ranges reaching up to $55 \%$ of static resistance, the structural stiffness degraded rapidly in the beginning and slower towards the end of the test, with stabilization at around $2 / 3$ of the original value. After three million cycles no failure occurred. Makita and Brühwiler [3] performed direct tensile tests on R-UHPFRC plates with three longitudinal rebars. The specimens were instrumented with extensometers. Under a stress range similar to the present study, the deformation was growing only in the beginning of the test, up to 500,000 cycles, remaining later almost constant until rebar failure. This finding was explained by stress transfer from UHPFRC to the reinforcement bar as the former loses stiffness due to the fatigue process. The decrease of local deformation range was observed for critical cross-section until failure of the rebar; however, it was not discussed in detail. The variation of deformation range along the specimen was attributed to scatter of bulk properties of UHPFRC in the specimen. Moreover, they reported about spalling of the cementitious matrix during the fatigue process. The same authors [4] tested also reinforced concrete slab-like elements strengthened with R-UHPFRC layer. Similarly, variation of deformation was observed, with highest deformation range in the section where the critical crack occurred. They inferred that strain and stress in rebars grew gradually leading to failure and determining the fatigue resistance of the structural element. However, the strain range in reinforcement bars was not directly measured.

For the sake of simplicity in design and modelling, the UHPFRC material is assumed to behave like a continuum up to the tensile strength $f_{U t u}$-when the localized fictitious crack is formed. It is called fictitious contrary to a real crack which cannot transfer the stress [5]. However, after reaching the elastic limit stress $f_{U t e}$, distributed matrix discontinuities, i.e. microcracks, appear. Observation of their opening may give important information on the fatigue process. Parsekian et al. [2] observed the largest microcrack opening amplitude. No change occurred under fatigue load range of $36 \%$ of static resistance, while rapid increase was observed under range equal to $55 \%$ of resistance. For the sake of comparison with the current research, a test on reinforced ECC
(Engineering Cementitious Composite) with PVA fibers is analyzed [6]. The structure of the matrix and microcracking behavior of this class of materials is similar to UHPFRC [7]. The distributed microcracks formed at early stage and their depth across the beam stabilized after few thousand cycles. Slow and constant growth of their opening continued throughout the test. The tensile strain in reinforcement bars and global deflection were almost constant, and the rupture of rebars marked the failure of the beam.

Although Distributed Fiber Optic sensors (DFOs) were used for in-situ monitoring [8], measurement of strain in reinforcement $[9,10]$ and discontinuities detection $[9,11]$ in R-UHPFRC elements, they were never applied in fatigue experimental testing of UHPFRC. However, DFOs proved their usefulness for fatigue monitoring of strain [12] and crack opening [13] in reinforced concrete. They allow for detection and measurement of microcrack opening in UHPFRC as well [14].

This paper discusses a fatigue test on a single R-UHPFRC beam, with strain measurement using extensometers (EXT), strain gauges (SG) and DFOs installed on reinforcement bars and UHPFRC. Special consideration is given to the cooperation of reinforcement and UHPFRC under tensile stress due to bending. Microcrack propagation and critical crack location are discussed. Finally, possible fatigue mechanism of UHPFRC in the structural member is presented.

As only one test is discussed, no conclusion on constant amplitude fatigue strength can be drawn. The paper does not discuss fatigue damage rate dependence on loading levels because of the same reason. It is assumed that the overall mechanism remains the same under all fatigue loading levels that lead to fatigue damage accumulation.

\section{Materials and methods}

The full-scale R-UHPFRC T-shaped beam was tested under four-point bending (Fig. 1). The beam was reinforced with one $\varnothing 34 \mathrm{~mm}$ steel reinforcement bar of class B500B according to Swiss and European standards [15, 16], anchored with $90^{\circ}$ hooks over supports and with UHPFRC cover $\mathrm{c}_{\mathrm{nom}}=17 \mathrm{~mm}$, thus $\varnothing / 2$, which is sufficiently thick from the mechanical point of view [17]. Considerably large diameter of 


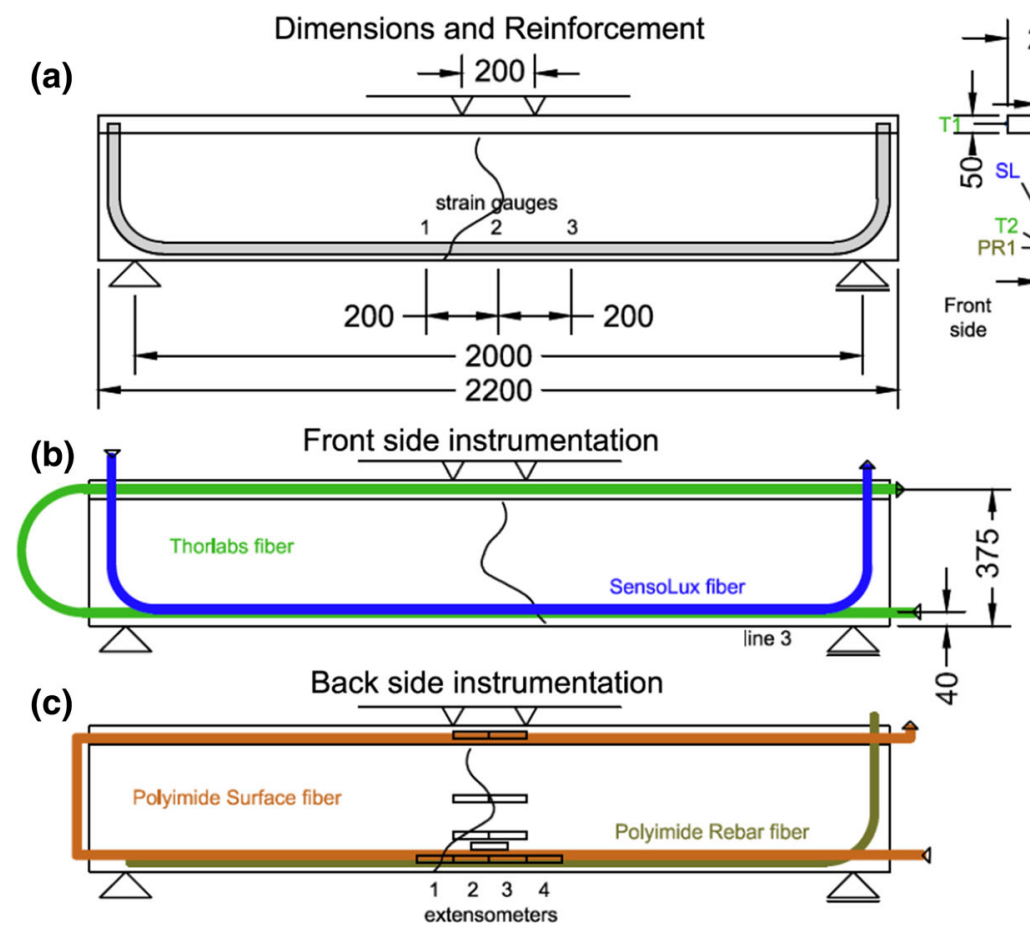

Fig. 1 Instrumentation of the beam with location of the critical crack; DFOs types: $P S$ Polyimide coating fiber on surface, $P R$ Polyimide coating fiber on reinforcement bar, $T$ Thorlabs fiber, $S L$ SensoLux fiber

reinforcement bar was chosen to facilitate installation of DFOs without a groove, which could lead to accumulation of stress and influence the fatigue performance of rebar. A steel I-beam of high rigidity distributed the load applied with a single hydraulic actuator. The load application points were placed at $100 \mathrm{~mm}$ from mid-span of the tested beam, symmetrically. A hinge and a force transducer were located between the actuator and the distribution beam.

The beam was casted with commercially available premix Holcim710® with $3.8 \%$ vol. $13 \mathrm{~mm}$ straight steel fibers of aspect ratio 65 . The following properties were obtained from material testing according to Swiss standard [18]: elastic limit stress $f_{\text {Ute- }}$ $=5.5 \mathrm{MPa}$, tensile strength $f_{U t u}=11.8 \mathrm{MPa}$, modulus of elasticity $E_{U t}=40.6 \mathrm{GPa}$, hardening strain at tensile strength $\varepsilon_{U t u}=3.5 \%$ and compressive strength $f_{U c}=140 \mathrm{MPa}$. The beam for fatigue testing was casted together with an identical reference beam to obtain the resistance under quasi-static loading.

The fatigue test was preceded with quasi-static displacement-controlled pre-loading. The load was gradually increased with loading-unloading cycles until the target constant fatigue force range was obtained, with $F_{\text {min }}=20 \mathrm{kN}$ and $F_{\text {max }}=250 \mathrm{kN}$. They represent respectively $4 \%$ and $53 \%$ of the static resistance (S) of the reference beam. Then, the system was switched to the force-controlled mode and the fatigue test started, with a frequency of $4.2 \mathrm{~Hz}$. To conduct measurements with fiber optics, the test was stopped periodically and a slow fatigue cycle $(0.025 \mathrm{~Hz})$ was executed. The DFOs measurements were performed during the 1 st and 2 nd cycles, then around every $10^{3}$ cycles until $10^{4}$ cycles (10 measurements), every $10^{4}$ cycles until $10^{5}$ cycles (10 measurements), every $5 \times 10^{4}$ cycles until $7 \times 10^{5}$ and finally every $1 \times 10^{5}$ cycles until failure. The test lasted for $8.76 \times 10^{5}$ cycles until failure of the beam.

The beam was instrumented with strain gauges, extensometers and fiber optics (FO) for distributed sensing (Fig. 1) Furthermore, the vertical displacement was measured with LVDTs (Linear Variable Differential Transformers) over supports and at midspan to obtain the absolute deflection of the beam.

The foil strain gauges were glued at the top of the reinforcement bar before casting, at mid-span and symmetrically $200 \mathrm{~mm}$ from mid-span. The extensometers with measurement base of $100 \mathrm{~mm}$ were 
glued to the surface of the beam according to Fig. 1c). Three types of DFOs were used in this research. The Luna ${ }^{\circledR}$ High-Definition Polyimide coating fiber of diameter $\varnothing 155 \mu \mathrm{m}$ was glued to the flat surface of longitudinal rib from both sides of rebar before casting. Same type of fiber, as well as the SMF-28 Thorlabs ${ }^{\circledR} \varnothing 900 \mu \mathrm{m}$ fiber with elastomer tubing, were glued to the surface of UHPFRC in a previously prepared groove, as described in detail in [14]. The SensoLux cable Ø2000 $\mu \mathrm{m}$ was directly embedded in UHPFRC during casting. This fiber was chosen for its mechanical resistance and was placed next to the reinforcement bar. Detailed information on all types of fibers can be found in [19].

The DFOs can be used for detection and measurement of discontinuities in the cementitious matrix, i.e. microcracks. The detection is based on observation of a strain peak signatures measured at the level of the optical fiber. Part of the optical cable which spans the discontinuity is stretched. However, due to a strain lag between the optical fiber core and its surrounding layers, measured strains form an exponential peak over a certain fiber length. The width of the peak depends on the structure of the fiber optics cable and glue. It is quantified with the strain lag parameter $\lambda$ $\left[\mathrm{m}^{-1}\right]$ determining the capacity of the fiber to measure microcracks at a certain range of crack openings [19]. The opening of discontinuity, traditionally called Crack Opening Displacement (COD), is measured by fitting the model to exponential peaks. The mechanical strain transfer equation between the UHPFRC and the core of fiber is used:

$\varepsilon_{f}(z)=\sum_{i=1}^{21} \frac{C O D_{i}}{2} \lambda e^{-\lambda\left|z-z_{i}\right|}+\varepsilon_{m}(z)$

where $\mathrm{COD}_{\mathrm{i}}$ is the opening displacement of each discontinuity $i$, parameter $\lambda$ is the fitted strain-lag parameter, $z_{i}$ corresponds to the position of each apparent strain peak, $\varepsilon_{f}$ is the apparent strain measured with DFOs, and $\varepsilon_{m}$ is the strain of host material. In this work, $\varepsilon_{m}$ was obtained using strain gauge measurements. The exponential equation is fitted to the most important apparent strain peaks using least square method. In this work, 21 microcracks were observed. This measurement method was developed and described in detail in [19] and demonstrated for UHPFRC in [14]. For the sake of brevity, the theoretical background is not presented here.

\section{Deflection and strain evolution}

Figure 2 presents the beam deflection $(\Delta \delta)$ and strain $(\Delta \varepsilon)$ ranges recorded with extensometers and strain gauges during the entire fatigue test. The strain range measured with strain gauges is smaller than the one measured with extensometers. This comes from the fact that strain gauges were installed at the top of the rebar while extensometers were located at level of axis of the rebar, thus $17 \mathrm{~mm}$ lower and is discussed later in this paper. The drops of values measured by all sensors indicate moments when the test was stopped to perform slow cycles and FO measurements.

In the first $1 \%$ of test duration, a rapid rise of strains and deflection ranges occurs. The simultaneous rise of values recorded by all sensors indicate that a phenomenon takes place along the whole length of beam, which can be associated with distributed microcracking. Before $10 \%$ of test duration is reached, strain and deflection ranges stabilize marking the end of stage I. It can be determined through observation of derivations of the recorded curves reaching zero. At $90 \%$ of test duration, a gradual rise of strain range, as well as of its derivation, in EXT2 and simultaneous fall in the neighboring EXT1 are observed, indicating the beginning of stage III. This is caused by the perturbation due to fatigue damage in that region, and possibly localized fictitious crack initiation within range of EXT2.

Figure 3 shows magnification of the last $10 \%$ of the fatigue test, and Fig. 4 derivatives of strain and deflection measurements during this period. At $95 \%$, the fatigue process in the region of EXT1 and EXT2 accelerates. During the last percent of the test, strain range in SG1 starts to increase indicating stress transfer between UHPFRC and rebar, and possibly an onset of crack propagation in the reinforcement bar. In the last $2 \%$ of test duration, the strain range of SG1 starts to increase rapidly as well as strain range of EXT1. This indicates the formation of a localized fictitious crack in UHPFRC due to interaction with the rebar. At this point, the global deflection range starts to increase as well. SG2 and SG3 show a decrease of strains while EXT1 to EXT3 reveal continuous rise of strain values. This could indicate a change of the static system due to fictitious crack propagation. However, EXT4 remains within its range of strains, showing that no global modification of stress-field occurred. 


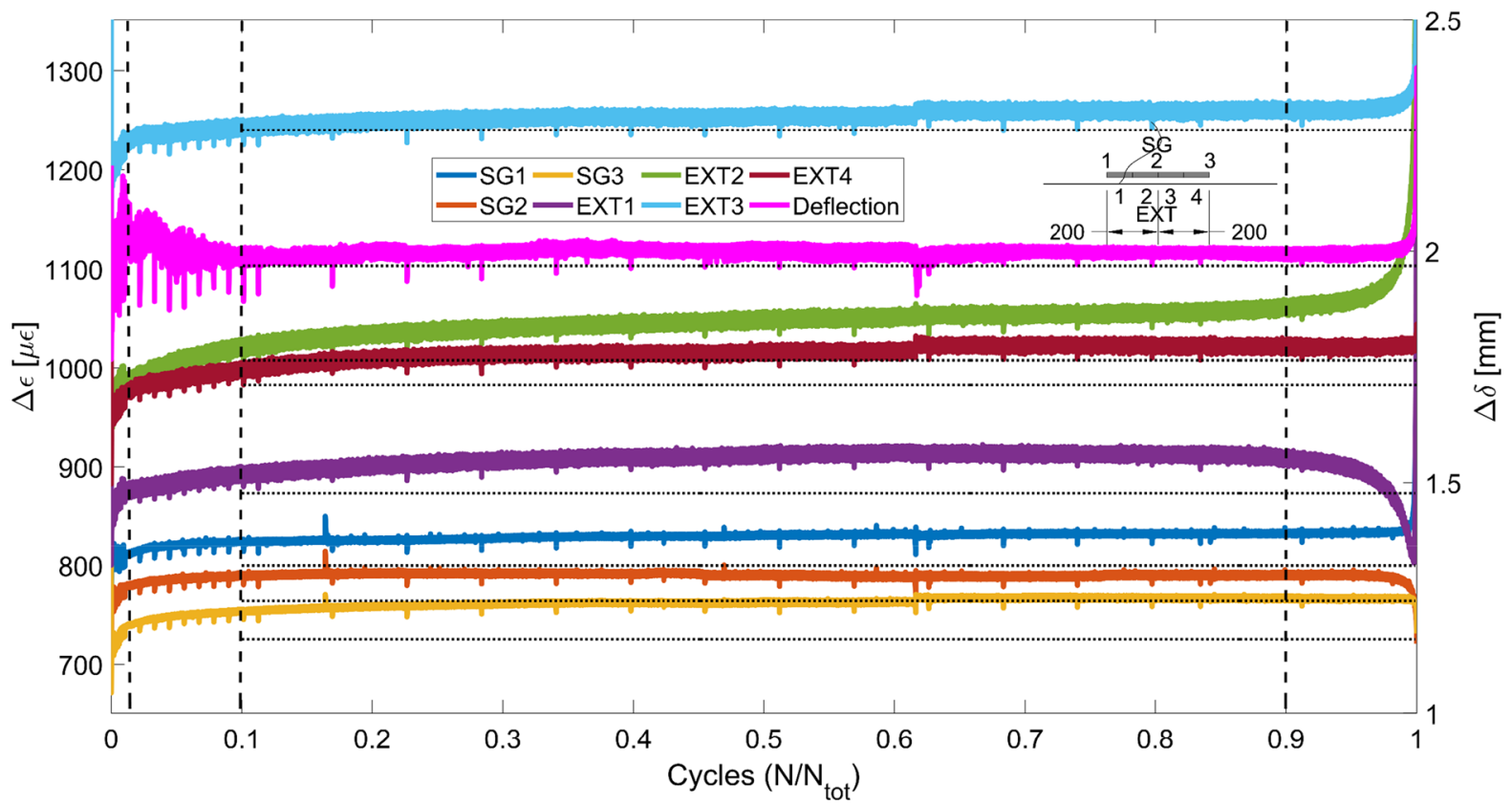

Fig. 2 Strain and deflection ranges during the whole duration of the fatigue test

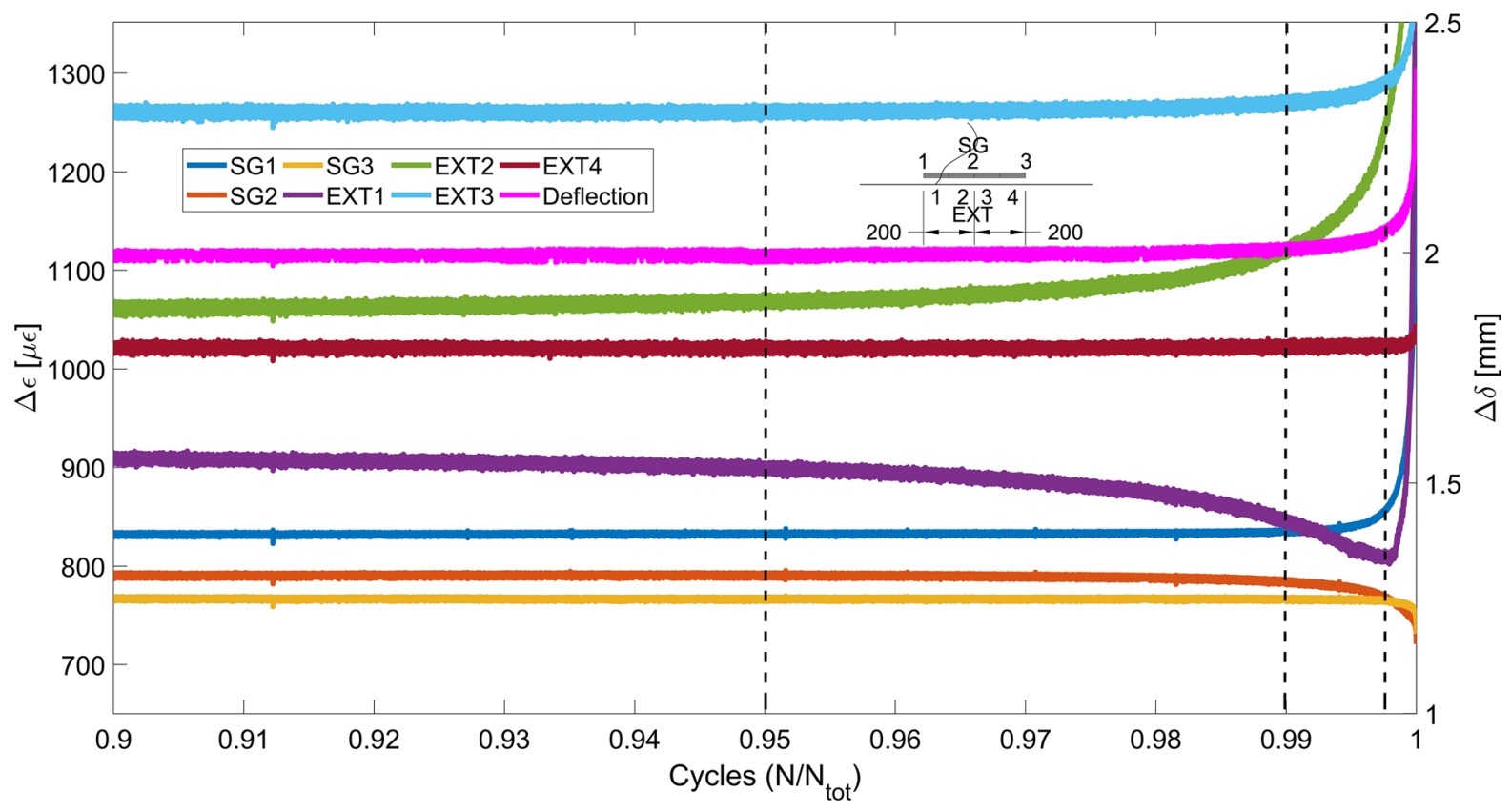

Fig. 3 Strain and deflection ranges during the last $10 \%$ of fatigue test

Therefore, the rise of strain in UHPFRC and reduction in the rebar most probably indicate unloading of the rebar.

At this moment, the fatigue crack in the rebar has well propagated, and part of the force previously carried by the rebar is transmitted to the surrounding UHPFRC. According to tests by Oesterlee [20], the peak bond stress of B500B rebar and UHPFRC is $\tau=44 \mathrm{MPa}$, for a mix containing $3 \%$ volume of fibers, with $f_{U c}=198.3 \mathrm{MPa}$ and $f_{U t u}=10.8 \mathrm{MPa}$. 


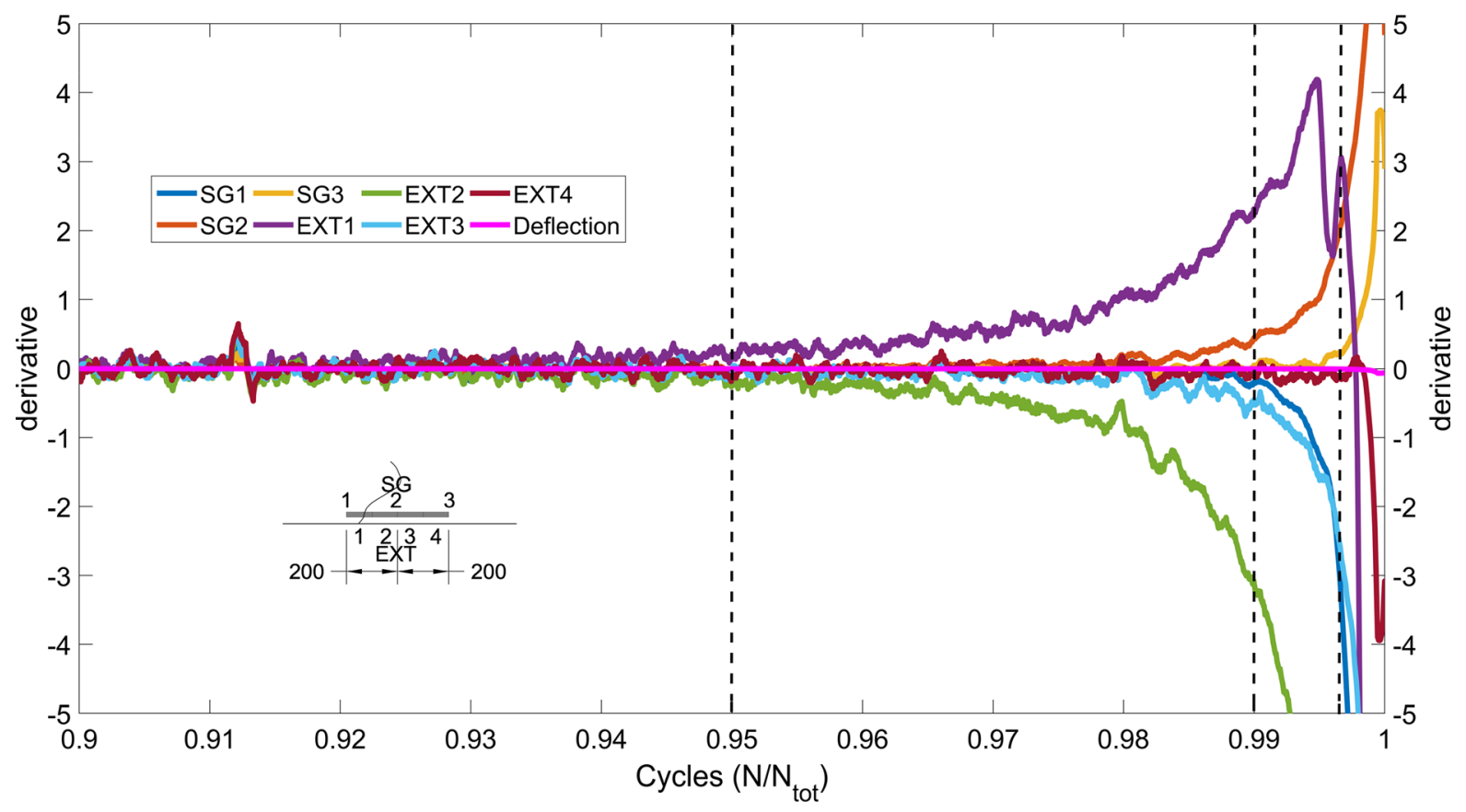

Fig. 4 Derivatives of strain and deflection ranges during the last $10 \%$ of fatigue test

The peak bond stress is slightly rising with increasing fiber content. Tests were done with $\varnothing 8 \mathrm{~mm}$ rebars using a specimen cross section of $50 \mathrm{~mm} \times 50 \mathrm{~mm}$, thus $c_{\text {nom }}=2.6 \varnothing$. As shown by Yuan and Graybeal [21], $\tau$ decreases with decrease of cover and increase of rebar diameter. For UHPFRC with $2 \%$ vol. of fibers and compressive strength after 14 days $f_{U c-}$ $=145 \mathrm{MPa}$, the average maximum bond strength was $23 \mathrm{MPa}$ and $20 \mathrm{MPa}$ for rebars $\varnothing 16 \mathrm{~mm}$ and $\varnothing 22 \mathrm{~mm}$ respectively, with $c_{\text {nom }}=2.0 \varnothing$. However, for the mix with $2 \%$ vol. of fibers, $f_{U t u}=11.5 \mathrm{MPa}$ and $f_{U c}=201.8 \mathrm{MPa}$, with $c_{\text {nom }}=1 \emptyset, \quad \tau=73.25 \mathrm{MPa}$ and $71.01 \mathrm{MPa}$ for $\varnothing 13 \mathrm{~mm}$ and $\varnothing 16 \mathrm{~mm}$ rebars respectively were obtained [22]. Lagier et al. [23] obtained $\tau=10.5 \mathrm{MPa}$ for rebar $\varnothing=25 \mathrm{~mm}$, mix with $4 \%$ vol. of fibers, $f_{U c}=110 \mathrm{MPa}$ and $f_{U t u-}$ $=12 \mathrm{MPa}$ for splice joints with cover $c_{\text {nom }}=\varnothing / 2$. Importantly, they tested direct rebar contact splices where the area of rebar surrounded by UHPFRC is reduced; this was not taken into account in the calculation of bond stress.

With SG1 $\varepsilon_{\max }=1200 \mu \varepsilon$ at $F_{\max }$, the stress in rebar is $\sigma_{\max }=246 \mathrm{MPa}$ with $E_{s}=205 \mathrm{GPa}$. As the fatigue crack in the reinforcement bar is located in the middle of EXT1, the length of the zone affected by the discussed phenomenon is around $150 \mathrm{~mm}$, barely reaching EXT3. Assuming complete loss of bearing capacity of reinforcement in the last stage, calculated average bond stress to transfer the total force carried by rebar to UHPFRC at this segment is $\tau=14.0 \mathrm{MPa}$. Taking into account small cover, large rebar diameter, and small slip of reinforcement, thus not full activation of the bond strength, the obtained value seems plausible [10]. Therefore, it can be deduced that $2 \%$, i.e. around 1700 cycles, before the end of test the reinforcement bar carries almost no force since the fatigue crack has largely propagated. The stress is therefore transmitted to UHPFRC causing its fast deterioration around the crack, localizing the failure section and leading to the collapse of the beam. Importantly, the reinforcement bar ruptures completely only at the very end of the test, which is confirmed by a loud noise. This is in accordance with observations of Makita and Brühwiler [3]. The middle part of the beam after failure is presented in Fig. 5. The critical crack is not linear as it follows the lowest energy path governed by fiber's content and orientation [17].

Figure 6 shows maximum and minimum strain in each cycle measured by four extensometers during the last $10 \%$ of the test. Slight rise of strains of EXT2 at both $F_{\max }$ and $F_{\min }$, as well as decrease of strain of 


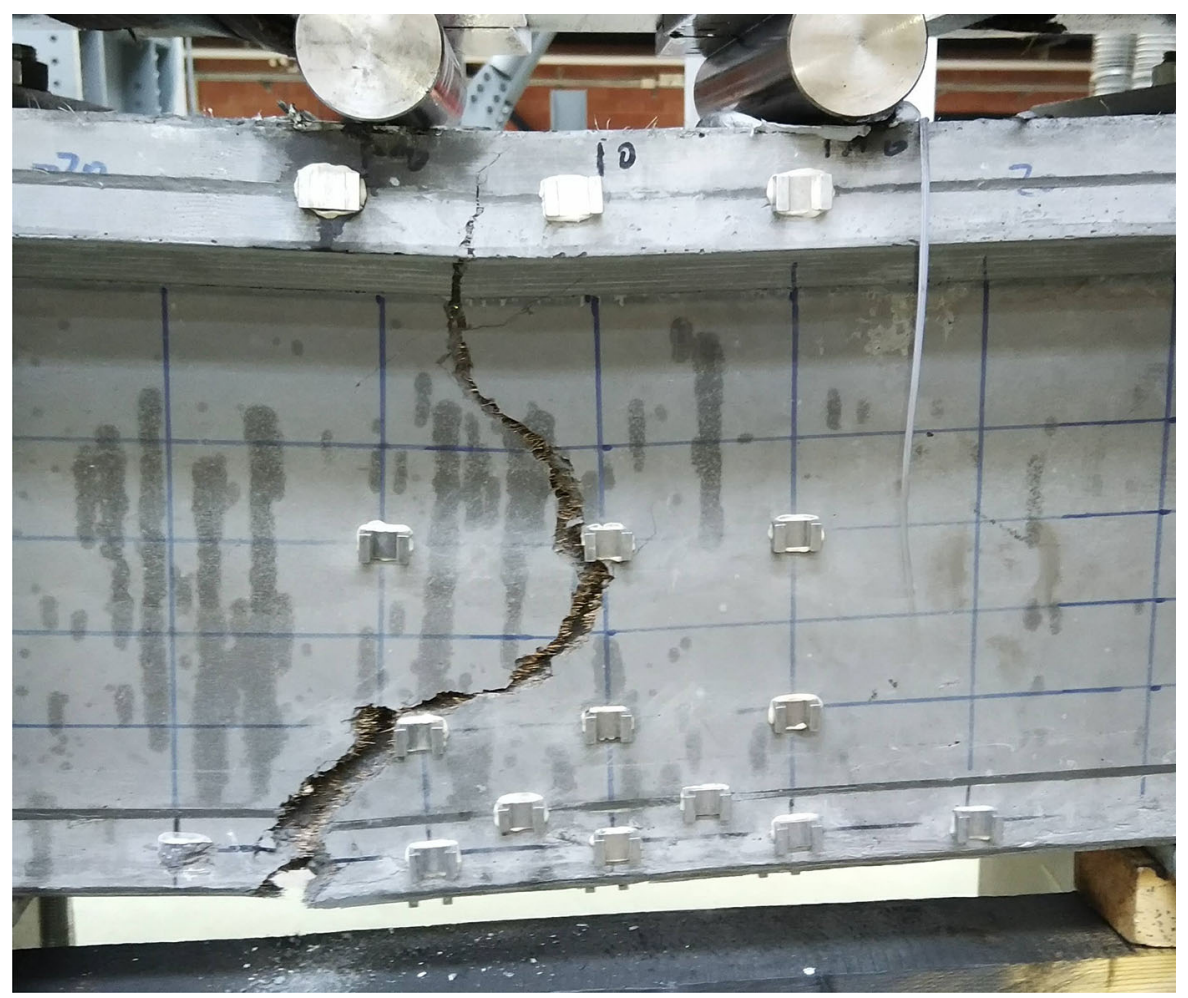

Fig. 5 Mid-span of the beam after failure with critical crack; visible metallic bases of extensometers and gray horizontal line where the DFOs is glued

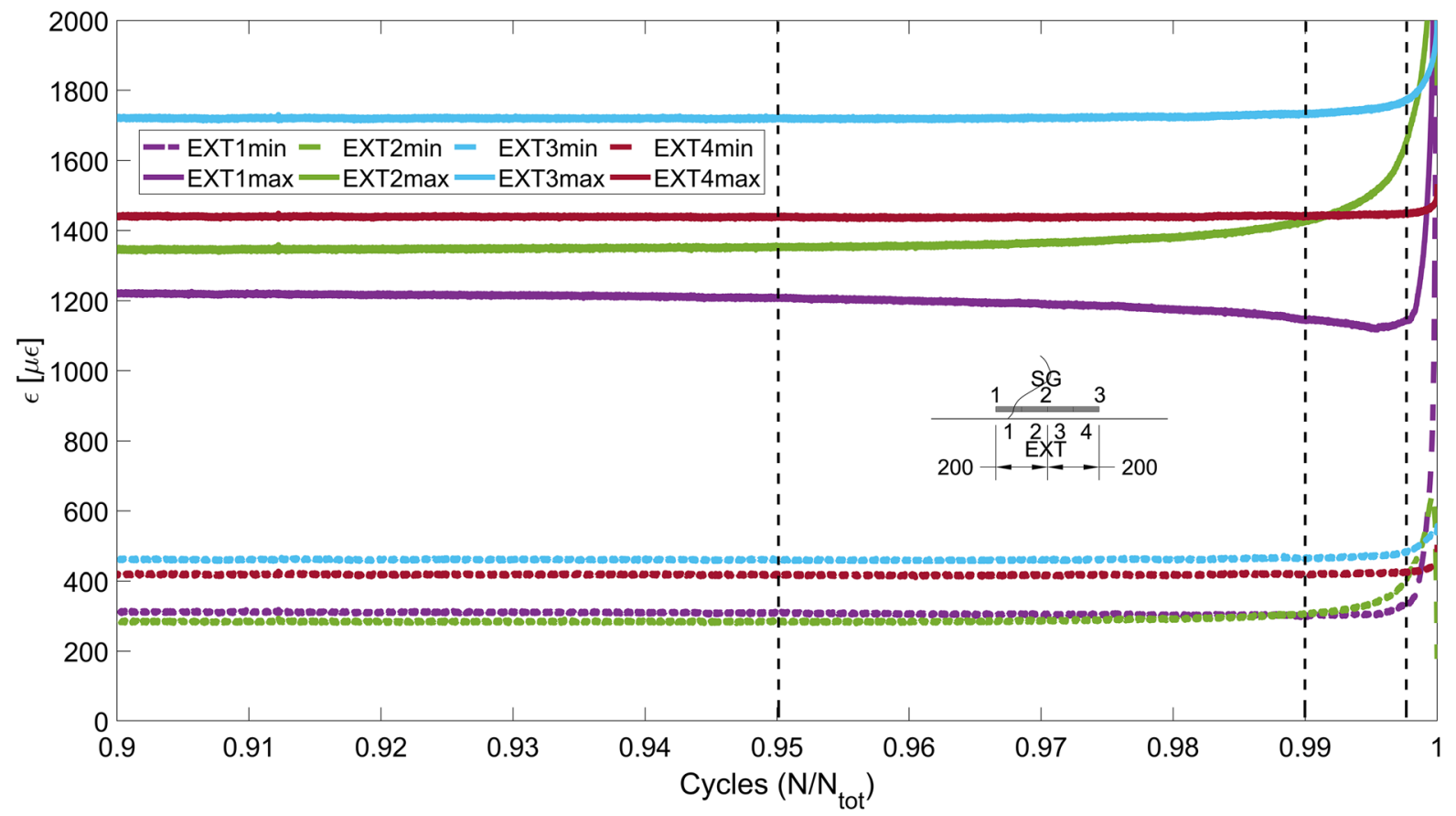

Fig. 6 Minimum and maximum strain in a cycle measured by extensometers during the last $10 \%$ of fatigue test 
EXT1 under $F_{\max }$, in the last $5 \%$ of the test confirm the previous observations of fatigue damage accumulation in UHPFRC and thus loss of stiffness. During the last $2 \%$ of test duration, both maximum and minimum strains at EXT1 and EXT2 rise as the stress is transmitted from the rebar to the UHPFRC. The quick pace of this stress transfer indicates a high rate of fatigue crack propagation in the rebar. This is in agreement with observations of Rocha et al. [24]. Thus, the onset phase of fatigue damage of reinforcement bar takes the majority of test duration. However, once the fatigue crack is initiated, it propagates quickly up to rupture.

Figure 7 shows the strain profiles at $F_{\max }$ as obtained by interpolation of extensometer measurements along the height of the beam (see Fig. 1) until $90 \%$ of test. Slight increase, of almost $20 \%$, of strain values in the tensile zone can be noticed. Overall, the strain distribution remains stable in test stages I and II.

The strain profile at $F_{\text {min }}$, presented in Fig. 8, shows much more variation. Cycle 0 indicates the moment when $20 \mathrm{kN}$ force is reached for the first time. At the end of cycle 1, when $F_{\min }$ is attained again, the strains are much higher. This is an effect of the part of
UHPFRC entering into strain-hardening under $F_{\max }$. This loading-unloading behavior is discussed in detail in [25]. After cycle 2, strains are further increasing along the whole cross-section, keeping the slope (curvature) constant. Towards the end of the test, gradual gain of strain can be noticed, with rise of the neutral axis position. Seemingly, the response of the beam under $F_{\min }$ is a much better indicator of the fatigue process than $F_{\max }$, which is discussed later.

\section{Strain distribution in the beam}

The strain measured with distributed fiber optics sensors, strain gauges and extensometers while reaching $F_{\min }=20 \mathrm{kN}$ for the first time is presented in Fig. 9. No peaks of strain are present in DFOs results as the cementitious matrix remains homogeneous and UHPFRC is in the elastic regime. EXT1 and EXT4 show lower strain than EXT2 and EXT3, since they lie outside of the constant bending moment zone. Strain gauges show lower strain than DFOs on rebars as they are positioned $17 \mathrm{~mm}$ higher, thus closer to the neutral beam axis.

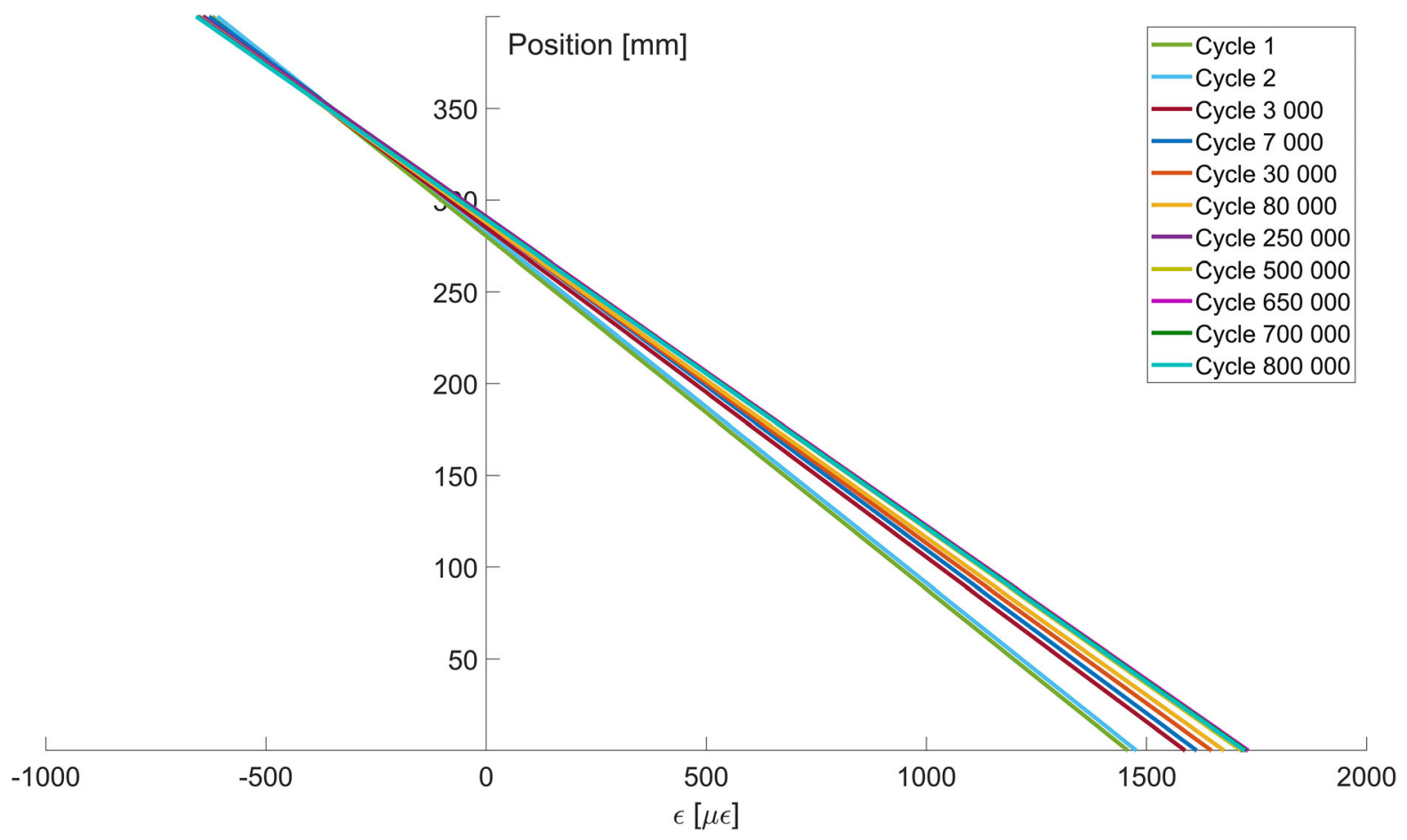

Fig. 7 Strain slopes in constant bending moment zone of the beam during fatigue test under $F_{\max }$ 


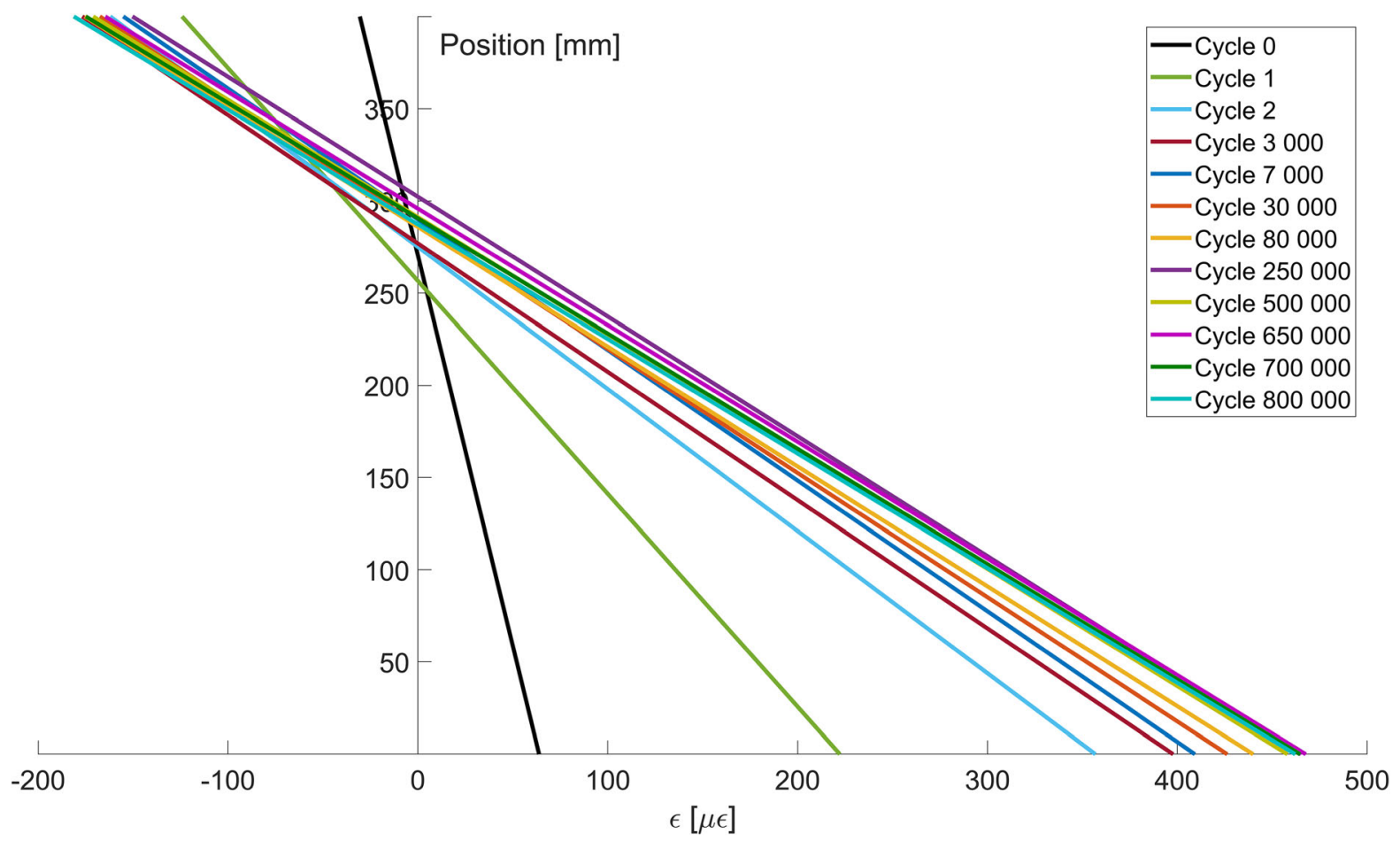

Fig. 8 Strain slopes in constant bending moment zone of the beam during fatigue test under $F_{\min }$

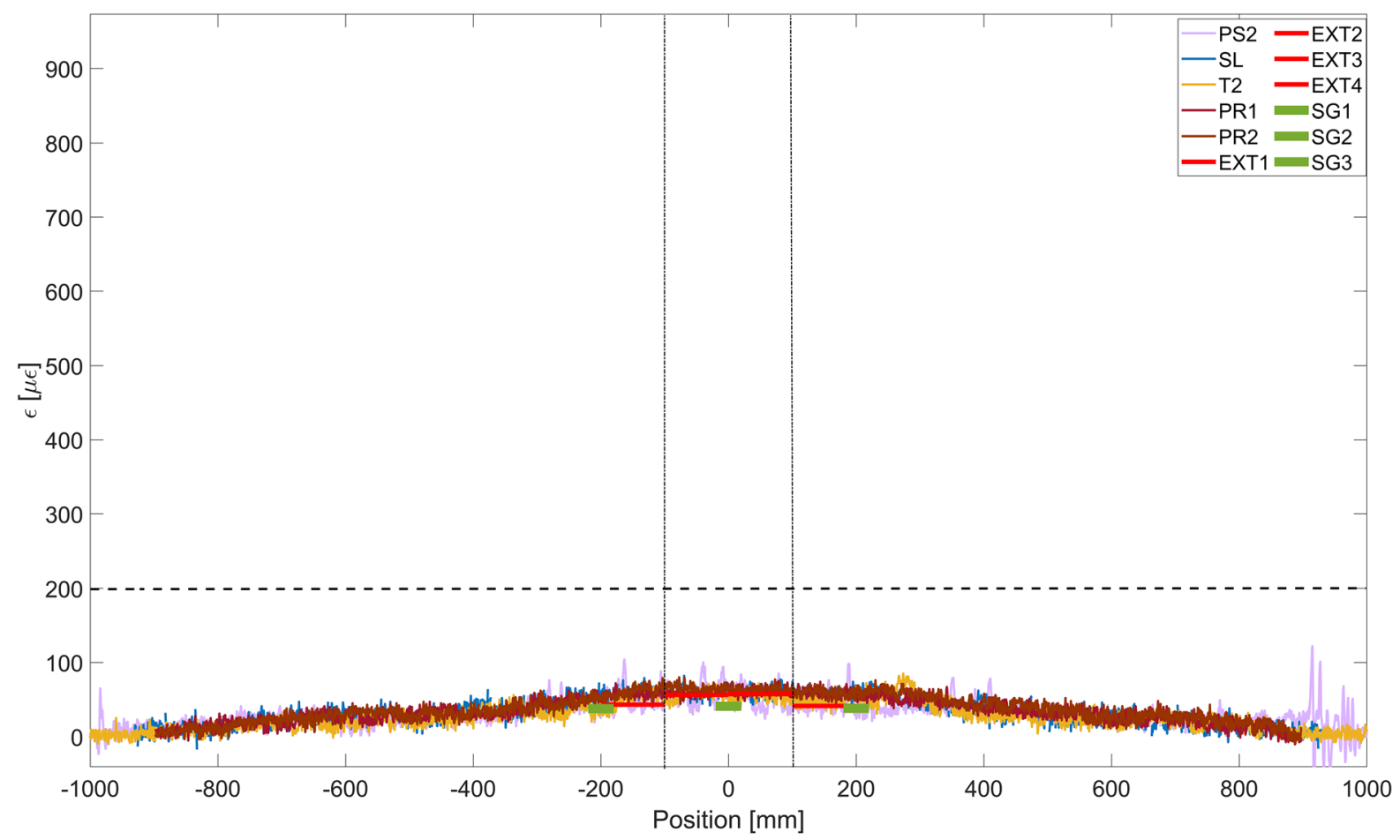

Fig. 9 Spatial strain distribution in the beam, 1st time at force $20 \mathrm{kN}$; constant bending moment zone marked with vertical dashed lines; acronyms as in Fig. 1; $200 \mu \varepsilon$ line for comparison 
Still in the first loading cycle, and under force of 45 $\mathrm{kN}$, UHPFRC enters into the strain-hardening domain where distributed microcracks are formed (Fig. 10). They are detected by regular strain peaks of external polyimide fiber measurements, with average spacing of $17 \mathrm{~mm}$. Few microcracks grow at higher rate and are visible along the $\mathrm{T} 2$ fiber line as well. They start propagating from the surface of the beam as the polyimide fiber lines PR1and PR2, as well as SensoLux (SL) cable keep measuring uniform strains. It is important to mention that the SensoLux cable is the least sensitive to microcracks among the chosen FO cables, as it is characterized by low value of the strain lag parameter $\lambda$ [19]. The variation of strain measured with extensometers provoked by microcracking is clearly visible and in accordance with [14] as well as with [11, 26, 27]. While EXT1, 2 and 4 show good agreement with T2 fiber measurements, EXT3 shows higher strain. This extensive microcracking occurs on the surface, as it is not visible with Thorlabs fibers located on the other side of the beam.

When maximum force $F_{\max }=250 \mathrm{kN}$ is reached for the first time, multiple microcracks are clearly visible (Fig. 11, left). The most advanced one is located around position $-50 \mathrm{~mm}$, visible with T2, SL and PR1 lines. It is however not visible with PR2 fiber and EXT2 on the other side of the beam (Fig. 1). This microcrack can be the reason behind fatigue damage accumulation within the range of EXT2 later on, as discussed previously. EXT3 keeps showing higher strain than the others. Since this microcracking front is not visible by any other sensor, it can be deduced that it does not reach the reinforcement bar and thus remains at the surface. Another large front is visible with Thorlabs fiber at $300 \mathrm{~mm}$, but only slight increase of strain on one side of rebar can be noticed. As far as SG1 fiber glued to reinforcement measure similar strain, SG2 and SG3 are 20\% lower. Strain distribution in the reinforcement bar presents clear trapezoidal shape due to four-point bending. The strain distribution at $F_{\text {max }}$ during the 2 nd cycle is not different from the one during the 1st cycle (Fig. 11).

The last DFO measurement was taken after $8 \times 10^{5}$ cycles, thus at $91 \%$ of the test. The overall rise in strain at $F_{\max }$ is around $20 \%$ compared to the first cycle (Fig. 11). There is no distinct strain peak in the

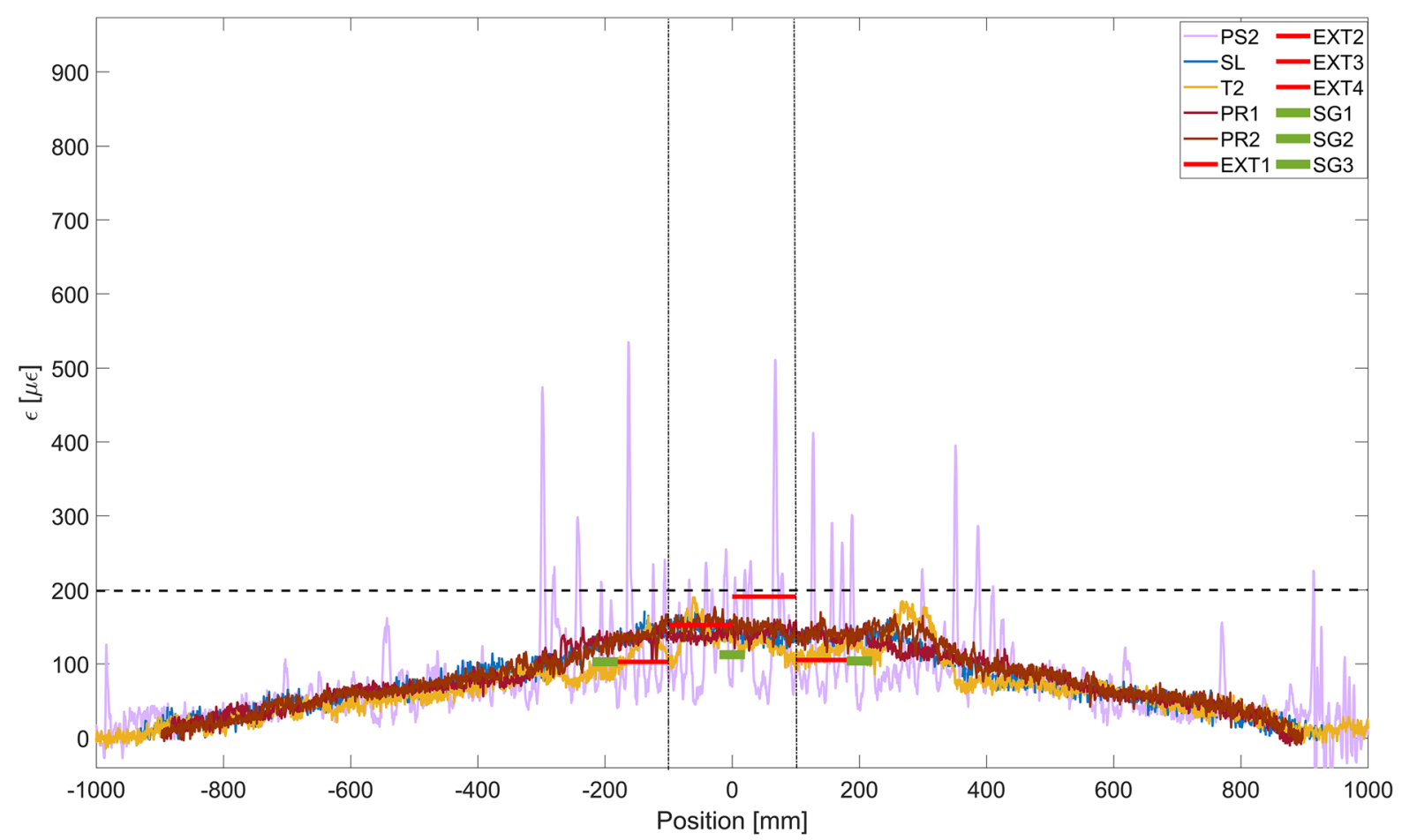

Fig. 10 Spatial strain distribution in the beam at force $45 \mathrm{kN}$; constant bending moment zone marked with dashed line; $200 \mu \varepsilon$ line for comparison 


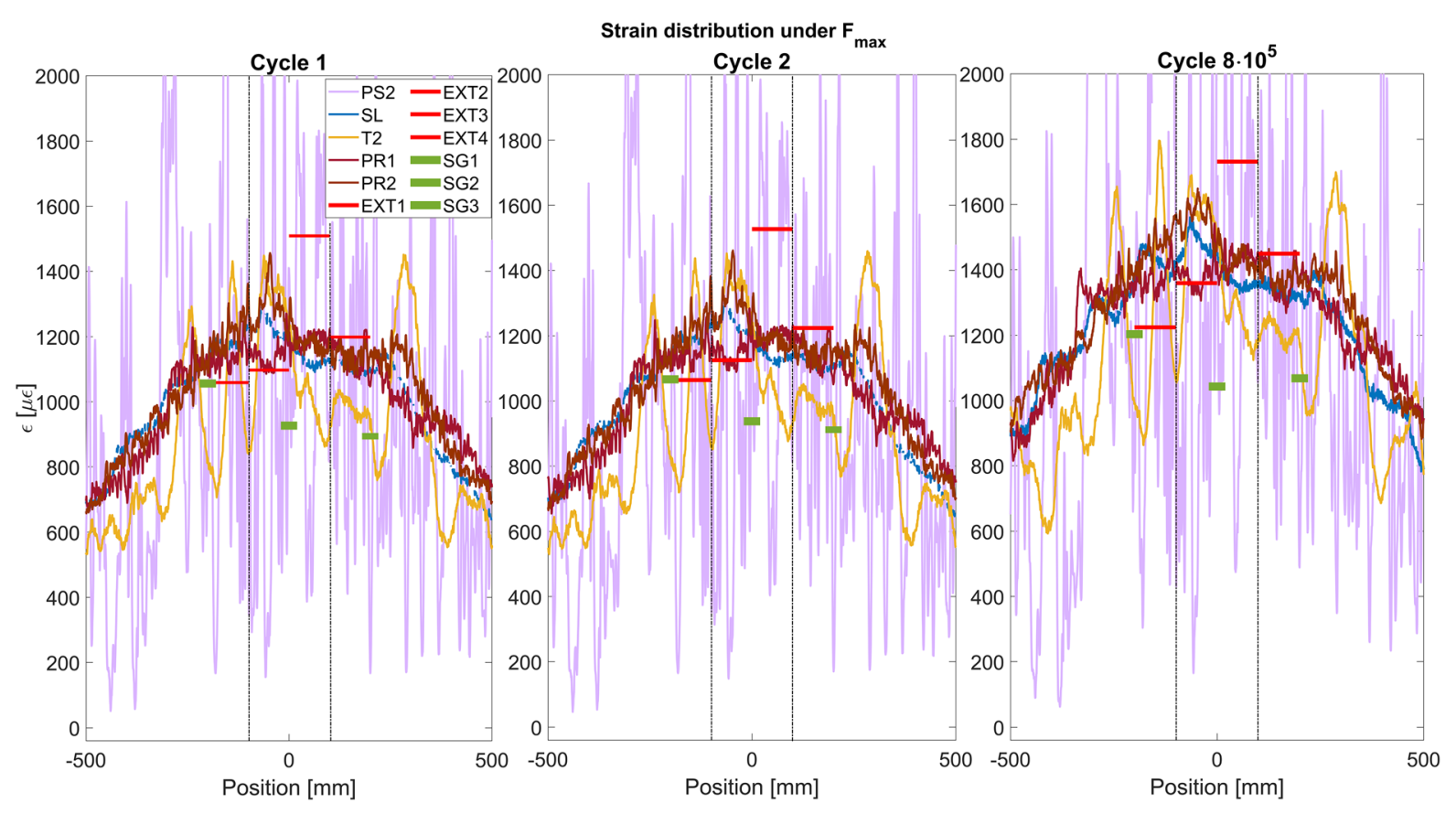

Fig. 11 Spatial strain distribution in the beam at force $250 \mathrm{kN}\left(F_{\max }\right)$ for 1st, 2nd and 800,000th cycle; constant bending moment zone marked with dashed lines

reinforcement bar, which indicates no advanced fracture process and continuity of reinforcement bars can be assumed at this stage.

At the end of the first full cycle, with $F_{\text {min }}=20 \mathrm{kN}$ (Fig. 12, left), the attained strains are much higher than during the first loading to this force (Fig. 9). This is due to the fact that UHPFRC which entered the strain-hardening domain does not come back to its original state after unloading, and residual strain remains [25]. As the microcracks close, the apparent strain peaks of Polyimide surface fiber remain in the same positions as under $F_{\max }$ (Fig. 11), but are much narrower and isolated. The peaks shown by the Thorlabs fiber keep similar width, with smaller apparent strain value. All the sensors, except of EXT3, show good agreement. The trapezoidal shape of the reinforcement strain profile is not evident anymore. This is due to the progressive modification of cross-section towards the constant-bending moment zone, as the zone of UHPFRC which entered previously into strain-hardening, grows. The closer to the midspan, the more the effect of strain rise at unloading is pronounced, producing the concave shape of strain plot (Fig. 13).
At the end of the 2nd cycle, further rise of strain values and convexity can be noticed. Strain in average is now about $66 \%$ higher than after the first cycle and $275 \%$ higher than at the first loading to $F_{\min }$. The reinforcement strain peaks are much more evident at position $-300 \mathrm{~mm},-50 \mathrm{~mm}$ and $300 \mathrm{~mm}$. The strain peaks are much better visible than after the $1 \mathrm{st}$ cycle, indicating that microcracks do not close completely after unloading.

During unloading of the beam in the last DFO measured cycle, further increase of strain values (Fig. 12) and concavity of strain profile (Fig. 13) are noticed. However, the difference between $8 \times 10^{5}$ cycle and 2 nd cycle is not as pronounced as between 2nd and 1 st cycle. The strains in the constant bending moment zone measured with Polyimide fiber on the rebar, SensoLux fiber and strain gauges are around $50 \%$ higher compared to the 2 nd cycle, $150 \%$ higher than after the 1 st cycle and $460 \%$ compared to the 1 st loading. Interestingly, the rise of strain is much less pronounced on the surface, where this rise is only about $20 \%$ compared to the 2 nd cycle. Importantly, although the relative increase of strain at $F_{\min }$ is much more important than at $F_{\max }$, the absolute values remain similar for the two loads. Therefore, the strain 

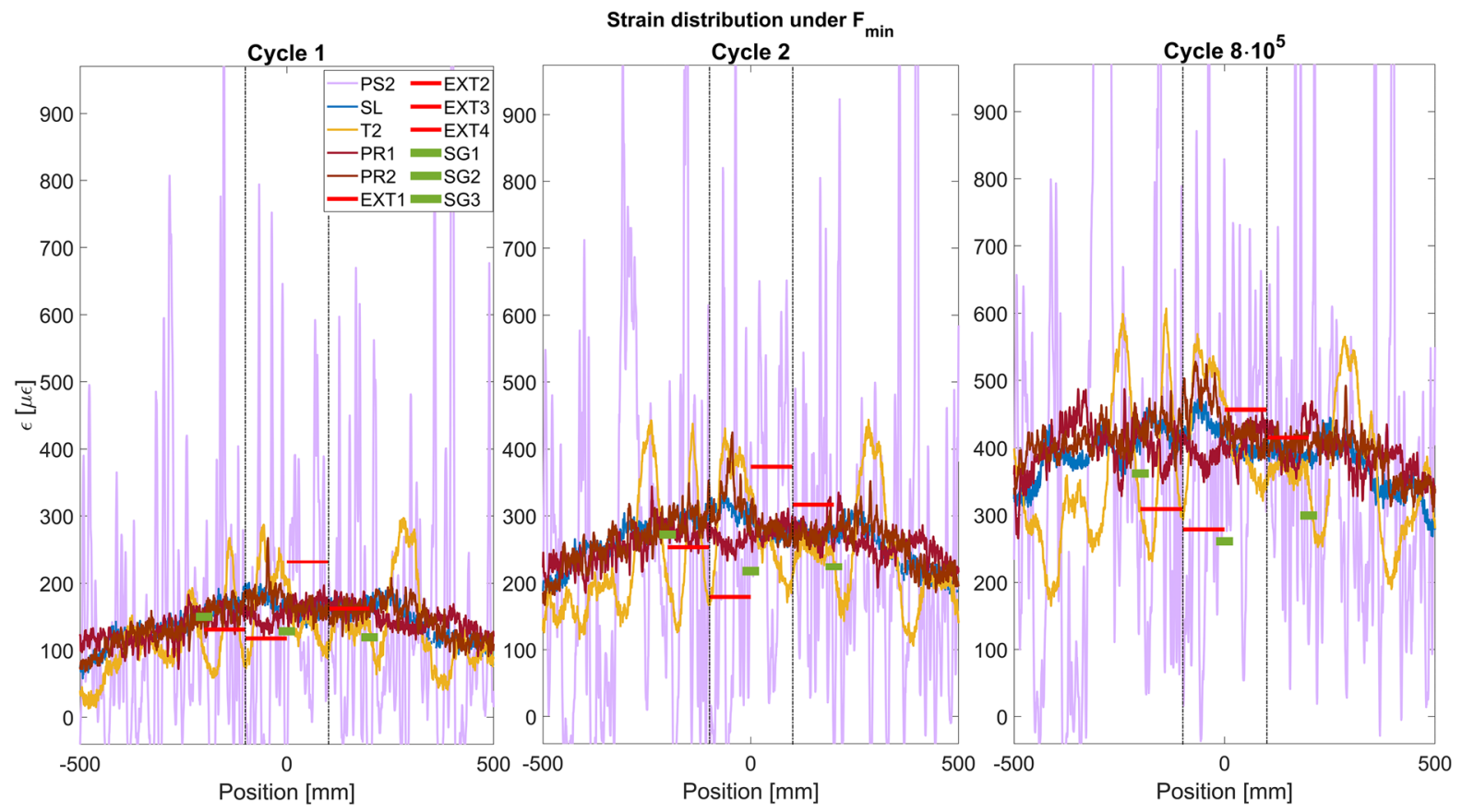

Fig. 12 Spatial strain distribution in the beam at force $20 \mathrm{kN}\left(F_{\min }\right)$ for $1 \mathrm{st}$, 2nd and 800,000th cycle, constant bending moment zone marked with dashed line

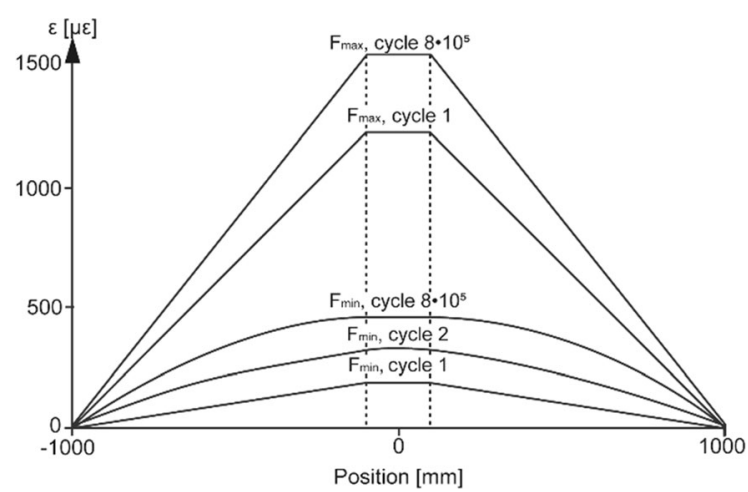

Fig. 13 Outline of strain distribution in the reinforcement bar during fatigue test

range during the fatigue stage II remains almost constant (Fig. 2).

The last DFO measurement was taken after $91 \%$ of test duration, thus before rapid strain range evolution and fatigue stage III started. Therefore, it cannot be of help in analyzing this last, dynamic part of the process.

\section{Matrix discontinuities opening displacement}

The Thorlabs fiber was used for measurement of microcrack opening (COD), similarly to [14]. Figure 14 presents the COD evolution during the fatigue test under both $F_{\max }$ and $F_{\min }$. The microcracks are formed in the very beginning, and their number remain constant during the whole test. The COD under $F_{\max }$ reaches its maximum at around 500,000 cycles and is slightly reduced later, which supports observations of Makita and Brühwiler [3] regarding strain stabilization. The COD under $F_{\min }$ grows continuously throughout the test. Until the last measurement (91\% of test duration) all the discontinuities remain in the microcracking domain $(<50 \mu \mathrm{m})$. This small evolution is the reason why the fatigue progress cannot be discerned through observation of microcrack propagation. At the same time, and considering that the maximum strain under $F_{\text {max }}$ remains below $1500 \mu \varepsilon$ with uniformly distributed microcracking as observed using DFOs, it can be deduced [28, 29] that UHPFRC under fatigue keeps its watertight performance at least for $90 \%$ of mechanical fatigue duration, i.e. strain remains smaller than $1.5 \%$. Importantly, even though 


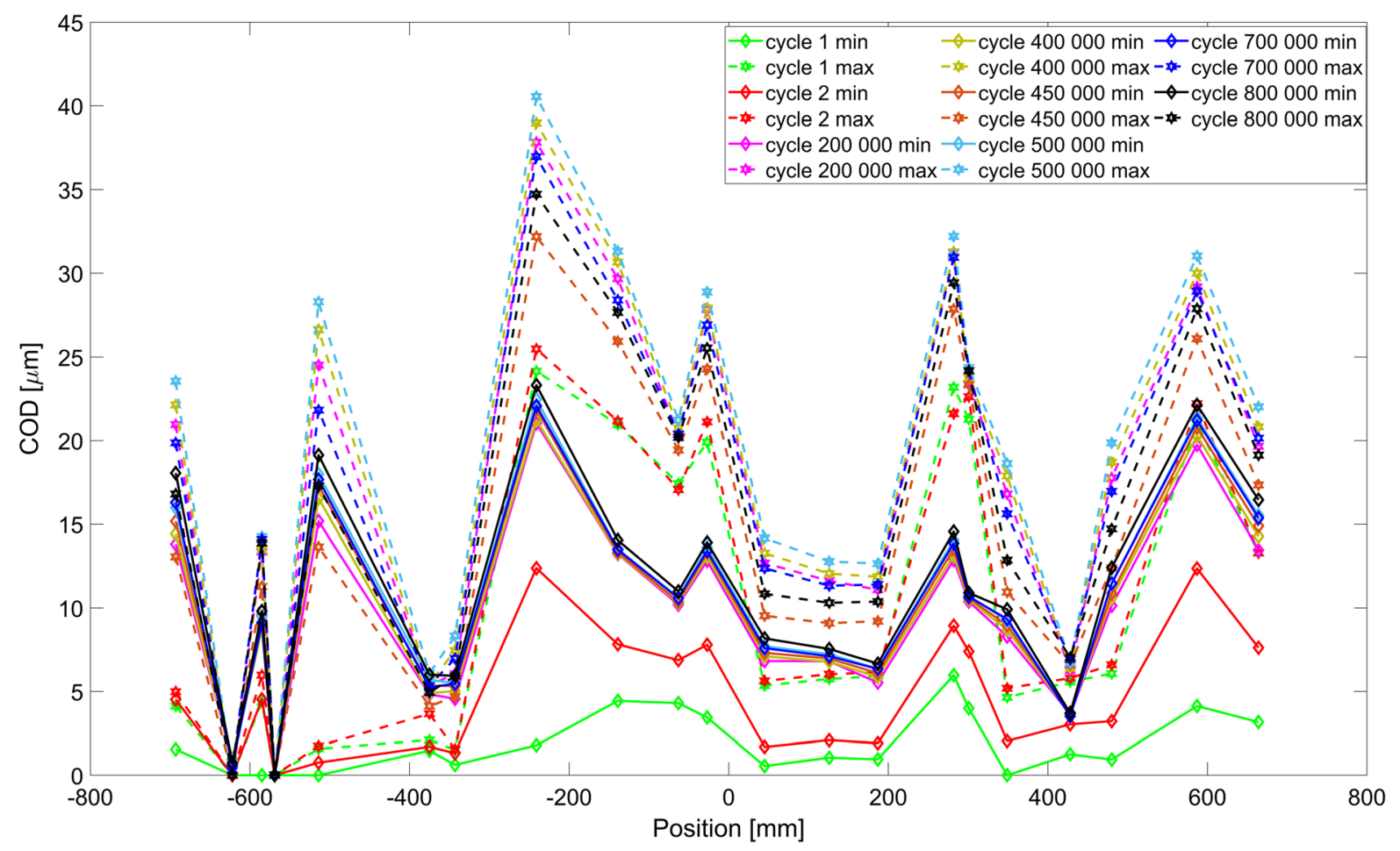

Fig. 14 COD of microcracks along the beam length during the fatigue test

the openings of these matrix discontinuities vary, their distribution along the beam is uniform.

\section{Description of a likely fatigue damage mechanism}

Due to loading-unloading cycles, part of the crosssection of the R-UHPFRC beam enters the strainhardening phase at $F_{\max }$, which leads to some plastic deformation. While unloaded to $F_{\min }$ the residual deformation is maintained, and compressive stress is activated in this zone [25]. Figure 8 reveals slight decrease of negative strain in the top flange of the beam during the test, with continuous growth of tensile strain in the bottom portion of web and rebar under $F_{\text {min }}$. Consequently, assuming linear elastic steel behavior and no reduction of reinforcement area, higher compressive stress has to be activated in the bottom part of the beam to fulfill the balance of forces in the cross section. One may suspect that this strain increase in the rebar could also be produced by a decrease of tensile bearing capacity in the UHPFRC. However, this would also affect stress distribution at
$F_{\text {max }}$, when the tensile contribution of UHPFRC is even more important. As presented in Fig. 7, this is not the case and the strain profile at maximum force remains approximately constant.

The increase of compressive stress in the bottommost part of the beam may be due to spalled particles of the matrix. These specks interlock inside microcracks when they open up at $F_{\max }$ and do not allow them to close completely at $F_{\text {min }}$. Spalling and pulverization of matrix due to pull-out of non-axially aligned fibers during tensile fatigue tests were observed by Makita and Brühwiler [26], similarly as shown in Fig. 15. The gradual increase in microcrack opening after unloading is observed in Fig. 14, supporting this hypothesis regarding the effect of spalled particles on the deformational beam behavior at $F_{\text {min }}$.

As mentioned previously, at $90 \%$ of test duration, lower strain increase (of 20\%) is recorded with external extensometers, compared to the 2nd fatigue cycle, than with internal DFOs (50\%), thus SensoLux and Polyimide on the rebar. This indicates increasing transversal strain gradient in the beam, which again can be attributed to the accumulation of pulverized matrix particles in the microcracks. On the surface, the 


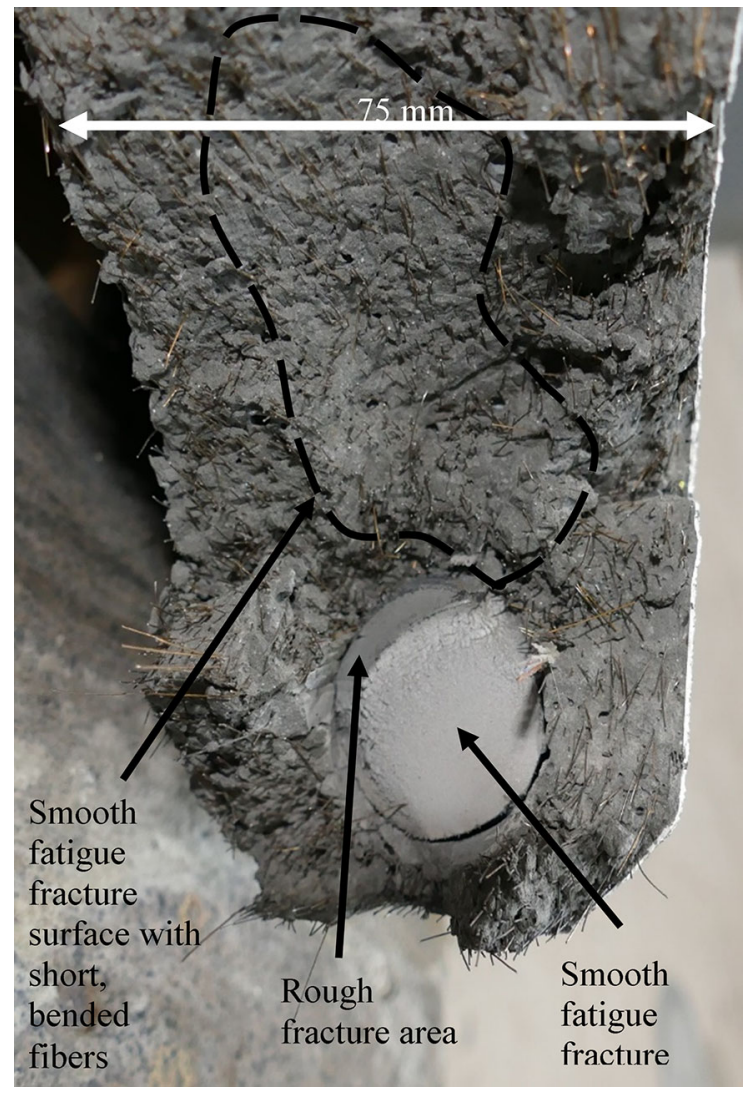

Fig. 15 Fatigue fracture surface of the bottom part of the beam

particles can be evacuated under $F_{\max }$ when the microcracks are opened. Indeed, during the whole test, there were flecks of cementitious matrix accumulating under the beam as visible in Fig. 5. However, powder particles entrapped inside the element cannot evacuate and the transversal strain gradient occurs. This is also confirmed by the smooth fatigue fracture surface of UHPFRC, as shown in Fig. 15, mostly occurring in the middle of the web. There, the fibers are bent due to fretting as already described by Makita and Brühwiler [26].

Typical smooth surface of steel reinforcement bar due to the propagating fatigue crack is visible in Fig. 15 as well. Small rough fracture area (around $15 \%$ of original rebar surface) indicates that reinforcement carries only little force at the moment of rupture. Assuming a rebar tensile strength $f_{u \text { - }}$ $=624 \mathrm{MPa}$ as obtained from material testing, only $30 \%$ of the force carried in the first cycles (with $\sigma_{\max }=246 \mathrm{MPa}$ ) can be transmitted by this reduced cross-section. This confirms the previously discussed stress transfer to UHPFRC during the last $2 \%$ of test duration.

\section{Conclusions}

This paper discusses in detail the fatigue test on a reinforced UHPFRC beam. The T-shaped member was loaded in four-point bending, with a fatigue force range equal to $49 \%$ of static flexural beam resistance and resisting 0.88 million cycles before fracture. The beam was instrumented with external extensometers, strain gauges on rebar and distributed fiber optic sensors glued to rebars, embedded inside and mounted on the surface of UHPFRC. Analysis of test results allow to draw the following conclusions:

- The fatigue deformation behavior of R-UHPFRC beam shows three stages: Stage I (0-10\% of total number of fatigue cycles) with rapid increase of strains; Stage II (10-90\%) with stable behavior showing only little increase in strain, and Stage III (90-100\%) with rapid increase of strain leading to fatigue failure.

- Fatigue failure of R-UHPFRC member is determined by the fatigue fracture of the steel reinforcement bar.

- Strain increase during Stages I and II is more important at minimum $\left(F_{\min }\right)$ rather than maximum $\left(F_{\max }\right)$ force in the fatigue cycle. This indicates that the fatigue damage of UHPFRC occurs under tensile-compressive stress reversal, possibly due to accumulation of pulverized, spalled particles of the cementitious matrix in microcracks.

- Fatigue damage occurs locally. During Stage III, local fatigue damage is visible in the strain range increase in the given section, but the reduction of stiffness is too small to influence the global member behavior, i.e. deflection.

- The fatigue damage process in UHPFRC and rebar does not necessarily take place in the same crosssection, but nearby i.e. in the range of around $100 \mathrm{~mm}$. However, the advanced fatigue crack propagation causes loss of bearing capacity of the rebar just prior to failure, overloading locally UHPFRC, which leads to localizing the final rupture in the same cross-section. This process 
takes place during sub-stage IIIa in the last $2 \%$ of test duration.

- The deflection range increases only in the last Stage IIIa, when the reinforcement bar can no longer transmit the tensile force.

- Beyond Stage I, no new matrix discontinuities appear. During Stage II, the maximum opening of matrix discontinuities remains stable, while the minimum opening constantly increases. These openings remain below $50 \mu \mathrm{m}$, therefore continuity of UHPFRC can be assumed.

\begin{abstract}
Authors' contributions Conceptualization: B.S, E.B.; Data curation: B.S.; Formal analysis: B.S.; Funding acquisition: E.B.; Investigation: B.S., A.B.; Methodology: B.S., A.B.; Project administration: B.S.; Resources: B.S., A.B., E.B.; Software: B.S.; Supervision: E.B.; Validation: B.S.; Visualization: B.S.; Writing — original draft B.S.; Writing—review \& editing: B.S., E.B., A.B.
\end{abstract}

Funding Open Access funding provided by EPFL Lausanne. This project has received funding from the European Union's Horizon 2020 research and innovation program under the Marie Skłodowska-Curie Grant Agreement No 676139 INFRASTAR.

Data availability The research data is available on request from the corresponding author (B.S.).

Code availability Code for data analysis is available on request from the corresponding author (B.S.)

\section{Declarations}

Conflict of interest The authors have no conflicts of interest to declare that are relevant to the content of this article.

Open Access This article is licensed under a Creative Commons Attribution 4.0 International License, which permits use, sharing, adaptation, distribution and reproduction in any medium or format, as long as you give appropriate credit to the original author(s) and the source, provide a link to the Creative Commons licence, and indicate if changes were made. The images or other third party material in this article are included in the article's Creative Commons licence, unless indicated otherwise in a credit line to the material. If material is not included in the article's Creative Commons licence and your intended use is not permitted by statutory regulation or exceeds the permitted use, you will need to obtain permission directly from the copyright holder. To view a copy of this licence, visit http://creativecommons.org/licenses/by/4.0/.

\section{References}

1. Brühwiler E (2016) "Structural UHPFRC": welcome to the post-concrete era. In: International interactive symposium on ultra-high performance concrete, Iowa State University Digital Press, Des Moines, Iowa, USA

2. Parsekian GA, Shrive NG, Brown TG et al (2008) Static and fatigue tests on Ductal ${ }^{\circledR}$ UHPFRC footbridge sections. SP 253:273-290

3. Makita T, Brühwiler E (2014) Tensile fatigue behaviour of Ultra-High Performance Fibre Reinforced Concrete combined with steel rebars (R-UHPFRC). Int J Fatigue 59:145-152. https://doi.org/10.1016/j.ijfatigue.2013.09. 004

4. Makita T, Brühwiler E (2012) Fatigue behaviour of bridge deck slab elements strengthened with reinforced UHPFRC. In: Proceedings bridge maintenance, safety, management, resilience and sustainability, London, CRC Press/Balkema, Stresa, Italy, pp 1974-1980

5. Hillerborg A, Modéer M, Petersson P-E (1976) Analysis of crack formation and crack growth in concrete by means of fracture mechanics and finite elements. Cem Concr Res 6:773-781. https://doi.org/10.1016/0008-8846(76)90007-7

6. Meng D, Zhang YX, Lee CK (2019) Flexural fatigue behaviour of steel reinforced PVA-ECC beams. Constr Build Mater 221:384-398

7. Li VC (2019) Engineered cementitious composites (ECC): bendable concrete for sustainable and resilient infrastructure. Springer, Berlin Heidelberg

8. Friedl H, Río O, Freytag B, Rodriguez Á (2010) Advanced bridge monitoring application for analysing actual structural performance of UHPFRC constructions-Wild Bridge. Czech Republic, Marianske Lazne, p 6

9. Schramm N, Fischer O (2019) Precast bridge construction with UHPFRC - Shear tests and railway bridge pilot application. Civ Eng Des 1:41-53. https://doi.org/10.1002/ cend.201800005

10. Marchand P, Baby F, Khadour A et al (2016) Bond behaviour of reinforcing bars in UHPFRC. Mater Struct 49:1979-1995. https://doi.org/10.1617/s11527-015-0628-0

11. Toutlemonde F, Simon A, Rivillon P, et al (2013) Recent experimental investigations on reinforced UHPFRC for applications in earthquake engineering and retrofitting. In: RILEM pro087: UHPFRC 2013-International symposium on ultra-high performance fibre-reinforced concrete, MARSEILLE, France, pp 597-606

12. Barrias A, Casas JR, Villalba S (2019) Fatigue performance of distributed optical fiber sensors in reinforced concrete elements. Constr Build Mater 218:214-223. https://doi.org/ 10.1016/j.conbuildmat.2019.05.072

13. Gu X, Chen Z, Ansari F (2000) Embedded fiber optic crack sensor for reinforced concrete structures. Struct J 97:468-476. https://doi.org/10.14359/4641

14. Sawicki B, Bassil A, Brühwiler E et al (2020) Detection and measurement of matrix discontinuities in UHPFRC by means of distributed fiber optics sensing. Sensors 20:3883. https://doi.org/10.3390/s20143883

15. EC2 (2005) Eurocode 2: Design of concrete structures-Part $1-1$ : General rules and rules for buildings 
16. SIA 262 (2014) Swiss standard SIA 262:2014 Concrete Structures

17. Sawicki B, Brühwiler E (2019) Static behavior of reinforced UHPFRC beams with minimal cover thickness. In: Proceedings of the 2IIS-UHPC-the 2nd international interactive symposium on ultra-high performance concrete, Albany, USA

18. SIA 2052 (2017) Technical Leaflet SIA 2052, UHPFRCMaterials, design and construction, Swiss Society of Engineers and Architects, Zurich

19. Bassil A, Chapeleau X, Leduc D, Abraham O (2020) Concrete crack monitoring using a novel strain transfer model for distributed fiber optics sensors. Sensors. https://doi.org/ $10.3390 / \mathrm{s} 20082220$

20. Oesterlee C (2010) Structural response of reinforced UHPFRC and RC composite members. PhD Thesis École polytechnique fédérale de Lausanne

21. Yuan J, Graybeal B (2015) Bond of reinforcement in ultrahigh-performance concrete. Struct J 112:851-860. https:// doi.org/10.14359/51687912

22. Yoo D-Y, Kwon K-Y, Park J-J, Yoon Y-S (2015) Local bond-slip response of GFRP rebar in ultra-high-performance fiber-reinforced concrete. Compos Struct 120:53-64. https://doi.org/10.1016/j.compstruct.2014.09.055

23. Lagier F, Massicotte B, Charron J-P (2016) Experimental investigation of bond stress distribution and bond strength in unconfined UHPFRC lap splices under direct tension. Cement Concr Compos 74:26-38. https://doi.org/10.1016/j. cemconcomp.2016.08.004
24. Rocha M, Michel S, Brühwiler E, Nussbaumer A (2016) Very high cycle fatigue tests of quenched and self-tempered steel reinforcement bars. Mater Struct 49:1723-1732. https://doi.org/10.1617/s11527-015-0607-5

25. Sawicki B, Brühwiler E, Denarié E (2020) Inverse analysis of R-UHPFRC beams to determine the flexural response under service loading and at ultimate resistance. Under review; J Struct Eng (submitted)

26. Makita T, Brühwiler E (2014) Tensile fatigue behaviour of ultra-high performance fibre reinforced concrete (UHPFRC). Mater Struct 47:475-491. https://doi.org/10. 1617/s11527-013-0073-x

27. Oesterlee C, Denarié E, Brühwiler E (2009) Strength and deformability distribution in UHPFRC panels. In: Proceedings of 4th international conference on construction materials: performance, innovations and structural implications: ConMat'09: August 24(Mon.)-26(Wed.), 2009. Nagoya Congress Center, Nagoya, Japan, pp 390-397

28. Charron J-P, Denarié E, Brühwiler E (2007) Permeability of ultra high performance fiber reinforced concretes (UHPFRC) under high stresses. Mater Struct 40:269-277. https://doi.org/10.1617/s11527-006-9105-0

29. Wang K, Jansen DC, Shah SP, Karr AF (1997) Permeability study of cracked concrete. Cem Concr Res 27:381-393. https://doi.org/10.1016/S0008-8846(97)00031-8

Publisher's Note Springer Nature remains neutral with regard to jurisdictional claims in published maps and institutional affiliations. 